\title{
Tercerización laboral: Perspectiva de una cronología de mercado
}

\author{
Job Outsourcing: Perspective of a Market Timeline
}

\author{
Gustavo Nixon Delacruz Giraldo \\ Abogado, magíster en Derecho; docente investigador de la Universidad Libre Seccional Cali, Colombia \\ Correo electrónico: gustavo.delacruz@unilibrecali.edu.co
}

\author{
Hernán Sandoval Ouintero \\ Abogado, especialista en Derecho Laboral y Derecho Constitucional; docente de la \\ Universidad Libre Seccional Cali, Colombia \\ Correo electrónico: hersanqui@unilibrecali.edu.co
}

\begin{abstract}
Resumen
El trabajo y las instituciones laborales posiblemente no se conciben dentro de un enfoque social esencialmente, en cuanto no está determinado como una prioridad dentro de una economía de mercado, y se subsume dentro de otros propósitos que permiten su adecuación, al estar finalmente direccionados por las fuerzas del mercado que condicionan las formas como se establecen esas relaciones y de cómo se han de regular, permitiendo establecer formas de organización del trabajo que faciliten la suficiencia del suministro de la fuerza laboral, en tanto que la organización de la producción debe no solo proporcionarse los medios materiales para el cumplimiento de su objeto, lo que implica, además, que en la correlación entre fuerza de trabajo y el fin de la actividad mercantil se termina estableciendo un vínculo no dentro del propósito de la realización de un fin social, por el contrario, estarán estimuladas por la necesidad, convirtiendo a la fuerza de trabajo en un insumo para el cumplimiento de un fin del mercado.
\end{abstract}

Palabras clave: Formas de trabajo, relaciones de trabajo, intermediación laboral, tercerización laboral, globalización, neoliberalismo.

\begin{abstract}
He work and them institutions labour possibly not is conceived within an approach social essentially, insofar as not is determined as a priority within an economy of market, and is subsumed inside others purposes that allow your fitness, to the be finally directed by them forces of the market that condition them forms as is established those relations and of how is have of regular, allowing establish forms of organization of the work that facilitate it sufficiency of the supply of it force labor, while it organization of it production should not only provide is them media materials for the compliance of its object, what implies also that in the correlation between force of work and the end of it activity commercial, is ends establishing a link not within the purpose of the realization of an end social, on the contrary will be stimulated by necessity, becoming an input for compliance to the labour force in an input for the fulfilment of an end of the market.
\end{abstract}

Keyworks: Forms of work, relationships, job placement, job outsourcing, globalization, neo-liberalism.

\begin{abstract}
Résumé
Le travail et les institutions laborales disponibles dans le monde entier, en tant que tel n'est pas à propos de l'un de nos partenaires. Les forces du marché qui condicionan les formes comme se establecen ces relations et de façon continue, de manière régulière, autorisant l'établissement des formes de l'organisation du travail qui facilitent la suficiencia de l'approvisionnement de la force de travail, en tant que l'organisation de la production ne doit pas être mise en valeur Les moyens matériels pour le résultat de l'objet, lo que implica, además, que dans la corrélation entre la force de travail et le fin de l'activité mercantil se terminent estableciendo un lien en ce qui concerne la réalisation de la fin sociale, par el Contrario, estarán estimuladas par la nécessité, se transformant en la force de travail en un insumo para el Compliance of un fin del mercado.
\end{abstract}

Mots-clés: Formas de trabajo, relations de travail, intermédiation, tercerisation laboral, globalización, néolibéralisme. 



\section{Tercerización laboral: Perspectiva de una cronología de mercado*}

Gustavo Nixon Delacruz Giraldo Hernán Sandoval Quintero

\section{INTRODUCCIÓN}

Desde las civilizaciones antiguas se implementaron formas de trabajo dentro de los estamentos que socialmente se aceptaron como instituciones que evolucionaron para servir al desarrollo socioeconómico, tales formas, revisadas desde una óptica humanista, estuvieron encaminadas al beneficio de una clase social, quienes evidentemente explotaron a otros para servirse de su fuerza de trabajo, y en ocasiones por ser este el único recurso o medio disponible con que contaban esos esclavos o siervos, era considerada una oportunidad que se aprovechaba a cambio de una retribución de protección que se traducía en comida o techo.

Pero podría resultar de estas formas de trabajo iniciales, un modelo de organización del trabajo en el que actualmente se esté incurriendo, como una práctica que simplemente ha mutado a lo largo de los cambios de los modos de producción, que en lo particular, resulta necesario el análisis actual de ciertos elementos que pueden resultar relevantes a la hora de hacer una comparación de las diferentes formas de trabajo, por denominarlas en primera medida, y de las relaciones de trabajo que hoy se han gestado con las nuevas tendencias económicas, con el advenimiento del Estado y el iuspositivismo.

Desde estas consideraciones se pretende indagar, primero, sobre aspectos cruciales de las formas de trabajo, abordando aspectos que podrían considerarse relevantes a la hora de encontrar una relación entre el mercado y la fuerza de trabajo antiguas, lo que implica el estudio de algunas civilizaciones que fomentaron sus prácticas.

Como segundo, se abordan aspectos que dentro del contexto actual se pueden considerar resultantes de los condicionamientos económicos que implican la utilización de formas contractuales atípicas y el surgimiento de otras figuras que obedecen a la organización del trabajo para el mercado.

Un tercer aspecto es considerar dentro de los efectos de la organización del comercio, como proceso con un enfoque global, y el neoliberalismo como un programa de reforma que se implementa para ajustarse a la globalización, que

* Este artículo es el resultado de la investigación adelantada por el grupo de Investigación María Cano - GILMAC de la Universidad Libre Seccional Cali, denominada: Tercerización de los corteros de caña en el sector azucarero del Valle del Cauca y sus efectos sobre las pensiones. 
repercute en las relaciones de trabajo, primando los objetivos económicos sobre los sociales, cuya construcción se da a partir de construcciones teóricas de críticos del sistema económico liberal.

El ejercicio implica, entonces, el análisis de instituciones como la esclavitud, para pasar a la época feudal, hasta llegar a la modernidad, cuyos procesos de industrialización marcan una nueva tendencia de libertad económica, sobre la que se edifican las estructuras que perduran hasta la contemporaneidad, encontrando una interrelación que tiene el comercio y con este el mercado como eje dinamizador de las políticas expansionistas de la globalización y del neoliberalismo, que de alguna forma desplaza las relaciones consustanciales de los hombres para someterlas a las reducidas formas de mercado.

\section{LAS FORMAS DE TRABAJO: LA ESCLAVITUD Y EL FEUDALISMO}

La denominación formas de trabajo, desde la proyección de este estudio, se adopta debido a la no existencia de una sistematización de normas laborales en los períodos anteriores al surgimiento del Estado, así mismo la denominación de la categoría relación de trabajo obedece a una noción jurídica que se aviene con el surgimiento del Estado, que independientemente de su definición, crea derechos y obligaciones recíprocas para las partes involucradas, empleado y empleador (Oficina Internacional del Trabajo, 2005).

En este orden de ideas, la esclavitud aparece desde una perspectiva teórica como una forma de trabajo institucionalizada, que claramente no es equivalente en todas las civilizaciones, pero que en su inicio se muestra como el aprovechamiento del servicio de los cautivos caídos en las guerras, y que representaron una mano de obra potencialmente útil, que además permitió la consolidación de las economías de los imperios antiguos como el egipcio, griego y romano. Así, la necesidad de movilizar fuerza de trabajo como lo señala Finley (1982) "estuvo presente siempre que una sociedad alcanzaba una etapa de acumulación de recursos y poder en unas cuantas manos" (p. 85).

Ahora, pensar en la esclavitud como institución dada su representación antigua, es considerar que en su original forma, pueda reflejar un estadio de las actuales formas contractuales en el ámbito del trabajo, de alguna manera se puede advertir una incidencia de los rasgos que la caracterizan, al ser el elemento humano el común en todas las formas de trabajo, tanto antiguas como actuales.

La Real Academia de la Lengua Española define la institución de la esclavitud como una forma jurídica que da al poseedor determinados derechos sobre la persona de un sujeto humano. El termino jurídico esclavo dentro de una relación económica, implicó que como sujeto de derecho privado se convirtiera en un bien alienable, quien como una forma de propiedad puede ser objeto de intercambio, 
y que como lo señala Marx (1982) la fuerza de trabajo se convirtió en una de las principales mercancías del mercado, siendo el esclavo la mercancía (p. 86).

Si el esclavo representase un objeto de cambio en el mercado, debieron existir personas o grupos de personas que se dedicaran a proveerlos. En este sentido, en la antigüedad el comercio, y con este, los esclavos, se vio avocado a formas de intermediación para que surtiese o se proveyera mano de obra, en tanto que la función que cumplieron los intermediadores era en su esencia tener disponible para el mercado fuerza de trabajo.

En efecto, uno de los ejemplos lo encontramos en el relato bíblico de José, al ser vendido a los mercaderes ismaelitas quienes surtían de esclavos a Egipto. En Génesis XXXVII, 26-28, refiere el texto que: “(...) cuando pasaron unos mercaderes madianitas, sacaron a José, subiéndolo del pozo y por veinte monedas de plata se lo vendieron a los ismaelitas que lo llevaron a Egipto".

Inicialmente, pareciere trascendental el comportamiento de los hermanos y lo reprochable que podría significar su conducta, pero no es este el propósito de la cita. Puede notarse que es un aspecto no evidenciado dentro de una sociedad, del que puede resultar importante el contraste de las necesidades de satisfacción de una economía enmarcada dentro de una forma de trabajo esclavista, que implicó indudablemente la intervención de un mediador para proveer la fuerza de trabajo.

El comercio de esclavos en la antigüedad, pudo verse circunscrito de alguna manera, a que su precio podría representar una ganancia futura que se podría obtener de su fuerza de trabajo, en tanto que el esclavo en sí mismo no agrega valor, el cual se obtiene solo cuando trabaja y produce al servicio de su amo (Zingarelli, 2004).

Puede resultar irónico el hecho de que en la antigüedad también se alquilaban los esclavos o que de forma temporal cumplían tareas para otros. Se puede tomar como particular ejemplo, en los estudios realizados por Zingarellii (2004) al referirse a unos papiros donde se compran 17 de días el servicio de una esclava, que entre otros apartes, además relata, sobre las transacciones que se realizaban delante del Kenebet, quien cumplía una aparente función de regulador, sin que implicara que estos fuesen propiedad de la institución, quien además se encargaba de dirimir los conflictos suscitados en torno al trabajo esclavo, en el marco de la transacciones comerciales.

En este sentido, el esclavo podía trabajar para uno y otro titulartemporalmente, cuya cesión se renovaría mensualmente durante un año justificando el precio de los contratos, resultando más favorable el alquiler que la compra, ya que si se alquila un esclavo temporalmente el valor podría alcanzar una paga inferior por sus servicios, contrario a lo que costaría comprarlo, alcanzando un $120 \%$ más (Zingarelli, 2004).

Este no era un panorama propio de los egipcios, siendo Roma otro de los escenarios sociales y culturales donde la esclavitud se acentuó como una institución, cuya causa principal fue el ser tomado prisionero en la guerra o como parte de su recompensa. En las Institutas 1, 2, 3 la esclavitud es una institución 
de derecho de gentes por la que contra lo natural, un hombre queda sujeto al dominio de otro. En igual sentido el Digesto 1, 5, 4, consigna "la servidumbre es una constitución del derecho de gentes, en fuerza de la cual se sujeta al dominio ajeno contra la naturaleza", así entonces, en Roma al esclavo se le denominaba siervo, y a la esclavitud servidumbre.

Por otro lado, el derecho romano recoge la figura jurídica del arrendamiento como un contrato consensual que se perfecciona por el acuerdo entre las partes sobre el objeto de la prestación y la retribución o contraprestación de la misma (Gómez \& Casal, 1996), y que en esencia es la locatio rei, que configura una cesión por parte del dominus, ejercido sobre un esclavo, para que el cesionario se beneficiara de la actividad laboral que este realizaba.

En tal sentido, el esclavo tenía jurídicamente la posibilidad de ser una cosa más en propiedad de su dueño, era posible considerar la cesión del goce de un esclavo y que el conductor restituía en un futuro convenido (Gómez \& Casal, 1996).

Esta cultura, sin embargo, no escapó a formas en la que se pone a disposición de otro u otros, la mano de obra de unos sometidos al dominio ajeno, por lo que representó también el que a manera de intermediador, el antiguo dueño del esclavo manumitido que no se aprovechaba del trabajo que el liberto estaba obligado a cumplir, podía ser cedido mediante arrendamiento a una tercera persona, desembocando en la denominada locatio conductio rei, situación que representó en su momento un atentado contra la libertad del liberto, a lo que se le puso fin con el edicto del Pretor Reutilio, y que más tarde finaliza mediante la Ley Aelia Sentía en el siglo 4 después de cristo (Gómez \& Casal, 1996).

De tal modo que quedaba prohibido el arrendamiento de la persona del liberto, en el sentido de que estaba sometido a una forma abusiva como una cosa, para el uso de su fuerza laboral, en la que el locator dispone de su propio liberto, puesto al servicio del conductor obligado a pagar una merces.

Sin embargo, resulta necesario aclarar conforme lo menciona Gómez \& Casal (1996) no eran los hombres libres los que frecuentemente participaban en la contratación laboral, sino los esclavos y libertos, debido a la poca consideración que se tenía al trabajo subordinado y remunerado, que en esencia viene dado por la entrega que hace el arrendador al arrendatario, este último, es quien debía devolver al esclavo o liberto al final, independientemente de quien se beneficiara.

Sin lugar a discusiones, es claro que el énfasis recogido en las líneas precedentes, es respecto del trabajador subordinado, y no de otro tipo de trabajadores, como el independiente, que para la época podría estar representado en el artesano $\mathrm{u}$ otro tipo de trabajador que ejerciere libremente su profesión, y que hoy se le denominan profesiones liberales; implicando para el trabajador dependiente la paga de una merces, y para el segundo una compensación económica denominada honorarios. Esto es lo que Gómez \& Casal (1996) enfatizan al explicar sobre el estar contratado mediante la locatio operarum, que exige una posición de subordinación, 
y en el segundo la locatio operis, quienes ejecutaban labores en una condición de independencia al realizar su trabajo.

Lo destacable de estas líneas permite tener presente, la importanteconstrucción respecto del origen de las relaciones de trabajo que se erigieron en la época antigua, y que por ser parte de ese legado del derecho occidental, es necesario resaltar al encontrar que todavía sigue de alguna forma presentándose vestigios de ese tipo de instituciones, pese a los avances del derecho en materia laboral.

Por otro lado, la crisis social política, económica, religiosa y cultural medieval, originada por la decadencia del Imperio Romano, se convierte en el artífice de la nueva realidad histórica que gesta los nuevos procesos en todos los campos, ascendiéndose a la denominada edad media, que al incorporar siglos de revolución comercial, muchos historiadores coinciden en llamar feudalismo.

La época feudal tiene diferentes matices tanto desde el campo religioso, político y económico, pero en el contexto como sistema de producción, tiene para su especial connotación una serie de figuras que implicaban un vínculo jurídico. El vasallaje consistía en uno de ellos, y que según Domínguez (2008), al término le subyacía la noción de ser "hombre de otro hombre", por cuanto el conde era el hombre del Rey, así como el siervo lo era del señor rural.

Tal figura, estaba precedida de un rito denominado "homenaje", en el que por un lado estaba el superior, quien era el señor, y por el otro, se encontraba el vasallo o encomendado, como forma especial de denominarlo. Así, tal ritual ponía de manifiesto la relación de subordinación de uno a otro, y que representa para quien está en situación de inferioridad el estar obligado al cumplimiento de las obligaciones particulares (Domínguez, 2008).

Así, con el propósito de desentrañar las relaciones de trabajo establecidas en este régimen, es importante primero establecer las relaciones económicas de la época enfocadas por conveniencia a la servidumbre, por lo representativo y por aglomerar el grueso de la población de la época, dedicada a labores agrícolas. No obstante, la realidad de los hombres libres en las ciudades se desarrollaba bajo la organización gremial de base artesanal.

Sin embargo, como lo establece Rodríguez (2014) acudir al auxilio de alguien como recomendado, tiene su origen en la edad media en los talleres de maestros que en estricto régimen, lograban evitar la libre competencia, control de precios, regulación de producción y creación de más talleres, restringiendo la entrada al gremio, obligando de esta forma a usar intermediarios a quienes pretendieran ser aprendices, porque los oficios se heredaban.

El señor dentro de la escala nobiliar, establece una relación con los siervos que cultivan la tierra, forma de vasallaje que constituyó una dependencia amplia entre las clases inferiores, cediendo al campesino en calidad de usufructo, de uso y disfrute a título de beneficiario y no a título de propietario, conjunto de campesinos sometidos al dominio y adscritos a un señorío, que subsisten gracias al producto de su trabajo, y de estos la aristocracia laica y eclesiástica (Domínguez, 2008). 
Si bien la economía de la época feudal es de subsistencia, por cuanto se producía no con el fin de intercambiar o vender los productos en un mercado autorregulado o independiente, el campesino de la época producía más para el autoconsumo de él y su grupo familiar, en tanto que el excedente producto del trabajo, obligaba al campesino a transferirlo como lo anota Domínguez (2008) bajo coerción jurídica, no mediante un contrato libre, pero sí como una forma de tributo para el señor feudal, sin la existencia de una negociación previa, ya que la apropiación nobiliaria estaba determinada por la sujeción jurídica entre el señor de la tierra y el campesino.

A diferencia del esclavo que tenía su propia economía basada en el trabajo personal, el campesino en la época feudal tenía un interés basado en su propio trabajo al contar con un medio consistente en la parcela, pero sujeto a la jurisdicción feudal donde el señorío está excluido del proceso de producción y los productores son los que detentan la posesión de los medios de subsistencia (Domínguez, 2008).

Por lo tanto entre el señor feudo y el siervo existía una relación que denotaba por un lado la cesión de la tierra, y por otro, la disposición de territorio para su uso, pero que beneficiaba a ambos, así como se beneficiaba la cúspide más alta de la aristocracia. Queda claro que existe entonces una mediación del señor para su rey, frente al campesino, con el propósito del mejor aprovechamiento efectivo de la fuerza laboral, dada las condiciones de la economía de subsistencia de la época, aspecto considerable que sin duda abre la puerta a la libertad de mano de obra de los individuos.

Ahora, el advenimiento de la industrialización no solo aparejo el surgimiento del derecho laboral, sino que trajo consigo también formas de organización para la mayor obtención de beneficios, tanto en los procesos productivos como de rentabilidad, en efecto ya estudiadas las anteriores instituciones en cada época, es claro que en estas se buscó el mayor provecho de la fuerza laboral, pero sin la mediación de un derecho que permitiese unas garantías mínimas.

Pero la ruptura del sistema económico feudal, dada la iniciativa capitalista y los procesos de acumulación que se tienen como los posibles genitores del crecimiento de la ciudad, el cual tendencialmente precipita el desaparecimiento de las instituciones feudales erigiendo el nuevo sistema, que por demás no solo concentra el poder económico sino que busca un espacio político como clase emergente, el burgués.

De este modo, para el momento existieron singulares formas de poner a disposición de otro u otros una fuerza laboral, lo que no dista mucho de la realidad actual que ese aprovechamiento se vea inmerso en muchas formas institucionalizadas y que las legislaciones acogen como la mejor forma de establecer las relaciones de trabajo, o de denominarlas dentro de los programas de Gobierno, formalización o empleo digno, en tanto que el beneficio, inicialmente, puede estar representado para el trabajador, pero en últimas es el empresario o empleador quien ha sacado mayor provecho sin distanciarse mucho del propósito que desde antaño se había ya trazado propio del mercado. 


\section{LAS FORMAS DE TRABAJOS PREHISPÁNICAS Y COLONIALES}

Para una mejor ilustración es conveniente dar una mirada a estas formas de trabajo anteriores, que podrían tener posiblemente una incidencia dentro de una perspectiva de mercado en las relaciones de trabajo que hoy se constituyen alrededor de un derecho que se forma para dar garantías de una clase social frente a otra, y que para tratar de establecer esa relación, nos detendremos un poco al análisis de lo que sucedió en nuestro continente americano, donde se establecieron formas de trabajo antes del surgimiento de un derecho laboral propiamente dicho, pero antecedido de unas formas esclavistas y señoriales como las ya relacionadas.

En la América prehispánica existieron manifestaciones de formas de trabajo representativas para la sociedad del entonces, y se encuentra en primer término a la mita, como uno de los tipos de trabajo inca anterior a la llegada de los españoles, que en su modalidad permitía ejecutar labores de forma rotativa de los mitayos, mano de obra que se proveía por las aldeas, y quienes regresaban posteriormente a sus localidades, al cumplir turnos de tres semanas (Escobar, 2014).

La encomienda aparece luego de la llegada de los españoles a las Américas, cuyo origen feudal ya referido, que a manera de recompensa otorgó la corona a los conquistadores junto a las mercedes tierras, en tanto que la encomienda facilitaba la mano de obra para la explotación de las mercedes de tierras, configurándose en elementos constitutivos del sistema productivo colonial (Valencia, 1987).

Las características de esta institución tienen como primer momento el apartar a los indios de los vicios y cristianizarlos, pero que entregados a los españoles colonizadores recibían a cambio de dicha cristianización sus tributos y trabajo (Escobar, 2014). Una de las características de la encomienda era la inalienabilidad, en tanto que el encomendero no podía repartir ni prestar sus encomendados; así mismo, el encomendero recibía a los indios, pero no los territorios, relación encomenderoindio sujeta a las disposiciones legales, que en primera medida era en perpetuidad.

La existencia de la encomienda depende de la fuerza de trabajo indígena disponible soportada en el dominio del sector privado como exitoso sistema de explotación, que incluso como lo relata Escobar (2014) a la expedición de las leyes nuevas por parte de la corona, se hacen evidentes sus intereses al hacer su manifestación de descontento contra las medidas del poder real.

Pero al contraste de la institución de la encomienda, es de resaltar como en la medida que el proceso mismo productivo incorpora nuevos métodos, lo era así el suministro de fuerza de trabajo para la realización de las tareas que exigían las labores agrícolas y mineras; luego como había que sustraer el mayor beneficio, surge la estancia como medida para obtener el doble de rentabilidad que en la encomienda común (Valencia, 1987). Así entonces, la estancia viene a constituir una de las formas productivas que emerge dando solución a un esquema de explotación menos eficiente. 
Por lo tanto, encomienda y mercedes de tierras tuvo la utilización de fuerza de trabajo indígena y el monopolio de la misma, así como la unidad productiva de la estancia surgió de la explotación de las mercedes de tierras, y tiene como efecto el que la mano de obra siga brindando las ventajas y beneficios al sistema económico colonial, esquema que, sin embargo, tiene un matiz especial, y que en particular implicó inicialmente tener a los indígenas en sus resguardos y posteriormente fueron sustraídos de su ambiente natural para ser sometidos a un régimen de prestación personal (Valencia, 1987).

Pero, aparte de estas modalidades de trabajo implementadas, Valencia (1987) resalta que los concertados surgen al llegar a la creciente ciudad un número de indios forasteros atraídos por el auge comercial, haciendo de esto parte de la evolución de la mano de obra especializada, debido a la demanda de productos agropecuarios, incorporando esclavos negros, y a la vez insertando a los forasteros, circunstancia que sin lugar a dudas deja entrever que la creciente mano de obra fue quizá también una salida eficiente a la decreciente población indígena que tuvo origen en la sobre explotación de esa población.

El comercio de esclavos negros africanos para la época muestra una manera eficiente de tener mano de obra disponible, por cuanto como lo refiere Mina (1975) era muy rentable, permitiendo que las clases explotadoras incrementaran y diversificaran su producción y los intercambios, en donde una vez el esclavo dentro de la economía esclavista este se reproduce al ritmo de los bienes que sirven para comprarlo (Organización de las Naciones Unidas para la Educación, la Ciencia y la Cultura, 1997, p. 20).

Este sería el preludio de lo que representase también para el capitalismo la disposición de fuerza de trabajo asalariada, toda vez que quienes vieron en la libertad de la compra y venta de esclavos una oportunidad de establecer monopolios por ser un próspero negocio, sería el equivalente a tener una rentable empresa de intermediación amparada en unas disposiciones legales para comercializar con la fuerza de trabajo.

Ahora, es claro y como lo han resaltado varios estudiosos del tema, la evolución y los procesos productivos junto con la fuerza de trabajo no es algo que se haya dado de manera igual para la América colonial, pero sí hay algo en común, y que como lo resalta Escobar (2014) estos eran medios eficaces para conseguir peones, procedimiento que generaba mano de obra abundante, que era lo que finalmente importaba.

No obstante, la evolución de las unidades productivas, gesta otra de sus formas, convirtiéndose la hacienda en uno de los modelos que da la entrada a otra forma de trabajo como el peonaje, que según estudios de Escobar (2014), son la antesala al trabajador asalariado, pero que además constituyó una eficiente forma de generar dependencia de estos y hacía que surgiese una relación paternalista frente a su patrono, y que como lo refiere Ostau de la Fond (2009) al ser estrecho el vínculo que se gesta entre la servidumbre y el hacendado, el paternalismo se vuelve. 
Pero el suministro de mano de obra en esta época colonial, además estaba sujeto al régimen de tierras que de alguna manera exigía para su explotación un número de trabajadores cuya dependencia perdurase, así como debiese perdurar el régimen de tierras y con estas la hacienda como unidad de producción.

Así, a finales del siglo XVIII, en Europa, surge la fuerza de trabajo asalariada, pero en América este proceso del trabajador asalariado solo se presenta relativamente a finales del siglo XIX e inicios del siglo XX, como también los cambios en los nuevos modelos organizacionales productivos y las nuevas tecnologías vinculados a los procesos productivos que también encausan la organización del trabajo, con la implementación de formas eficientes puestas a disposición del mercado, bajo el estricto control y disciplina impuesto por el patrono o sus representantes legales, sin recursos legales y con los rudimentos de la protección pública (Hobsbawm, 2007, p. 213).

\section{RELACIONES DE TRABAJO, INTERMEDIACIÓN LABORAL Y TERCERIZACIÓN LABORAL}

La estructuración de un derecho común, erige a finales del siglo XIX un marco jurídico que edifica una rama del derecho cimentado en las relaciones de trabajo, campo donde se establecen las relaciones entre trabajador y empleador, denominado derecho del trabajo, con autonomía e instituciones propias reguladoras del contrato de trabajo como institución base para las relaciones entre la clase trabajadora y la empresarial.

Esto tiene una significación, al estar encontradas en los diferentes momentos en las etapas del desarrollo social y económico que se han expuesto, en tanto que pone en evidencia que ha existido la intermediación desde siglos atrás, resultado prevalente de la iniciativa privada que sin más subyuga a aquellas personas que carecen de libertad económica, cuyo bien representado en su fuerza física o intelectual, es en ocasiones lo único que lo acompaña a la hora de establecer una relación de trabajo.

En este sentido, la relación de trabajo encuentra en el panorama mundial a inicios del siglo $\mathrm{XX}$, la discusión centrada en la naturaleza del trabajo como un nuevo derecho dentro de la teoría contractualista, al ser analizada en un contexto como un fenómeno jurídico objetivo (Jaramillo, 2010), cuya denominación encierra en sí misma su origen germano y romano, al descender de un tronco común como lo es el derecho civil y con este el contrato, que en el nexo entre privados como lo señala Bylos (1998) aplicado al trabajo gobernado en cuanto factor económico dirigido por manos invisibles, hacen del trabajo una mercancía, sujeto a la ley de la oferta y la demanda.

No obstante, la creciente demanda tanto de bienes como de puestos de trabajo, trae consigo una oportunidad para la creciente población de los centros urbanos, a los que Marx (1999) denomina como jornaleros que ofertan su trabajo, donde el capitalista se apropia ya no de él sino de su trabajo, contrario a lo acontecido a 
las ya referenciadas épocas, donde el amo se apropiaba de su esclavo y el feudo de la producción de su siervo.

Ahora, puede resultar precipitado afirmar, que así como en la antigüedad el alquiler de esclavos representó un mayor beneficio para el amo; como también lo fue para el feudo, en la relación con su siervo en condición de usufructo de la tierra; o como lo fue para el colono español la mita, la encomienda, la estancia, el peonaje para el trabajo en la hacienda; lo es hoy, el que como formas institucionalizadas y reconocidas mediante disposiciones legales, el que puedan constituirse agencias de empleo y empresas temporales de servicios.

Lo particular de estas figuras inclusive con reconocimiento jurídico no es solo la relación de efectividad para el logro comercial, sino el logro efectivo del suministro de fuerza laboral puesto a disposición del mercado, como una dimensión totalmente opuesta a lo que la Organización Internacional del Trabajo OIT consignó en uno de sus apartes de su constitución, al referir que el trabajo no se debe tener como una mercancía.

Frente a esto último, no parece ser así, toda vez que en la realidad, si bien las agencias de empleo y las empresas de intermediación no tiene aparentemente como fin comercializar fuerza laboral, por cuanto, con el denominado ofrecimiento en su objeto social de venta de bienes o servicios para la satisfacción de una actividad comercial en una de las empresas contratantes, finalmente las colocadoras de empleo, intermediaria, beneficiaria y usuaria, tienen como principal objeto el beneficio comercial, por encima de la calidad del trabajo de sus trabajadores, cuya esencia y objetivo es el vínculo contractual comercial que se establece.

Pero visto de fondo, el objeto de las intermediadoras de empleo reviste un éxito que finalmente tiene que ver con la puesta a disposición de una empresa contratante o usuaria de la fuerza de trabajo, que si bien en inicios pudo resultar muy eficiente dentro de las tareas que realizaban instituciones del Estado, a la par con el surgimiento de un derecho laboral, cabe preguntarse hoy por hoy, porque es una actividad comercial que la realizan de manera exitosa miles de empresas a nivel mundial, cuyo reportes de cifras en ingresos es astronómico?

Lo anterior se puede soportar en el estudio que al respecto adelantó la Confederación Sindical de Trabajadores y Trabajadoras de las Américas CSA \& Confederación Sindical Internacional CSI (2013), donde la actividad comercial de las agencias temporales de trabajo - ATT, proporciona mano de obra a empresas públicas y privadas y cuyo margen de beneficios es elevado.

Desde este punto de vista, la lógica del capital descuida las actividades cuyo producto o resultado no es medible con los criterios de rentabilidad y rendimiento, por estar dentro de un ámbito en el que la producción comercial o el intercambio comercial que incluye la ganancia o el intercambio de bienes y servicios, están más allá, por encontrarse dentro de la esfera de las necesidades humanas no traducibles en términos de demanda que no pueden comprender o hacer parte del mercado (Gorz, 1991). 
De este modo se pueden encontrar estrategias organizacionales del trabajo en las empresas que flexibilizan como lo anota Gorz (1991), por un lado, existiendo un núcleo de trabajadores estables que aceptan la movilidad profesional cualificados por la casa mediante la formación interna, de los que depende la firma y viceversa. No obstante, alrededor de ese núcleo estable fluctúa la mano de obra periférica que está sometida a la eventual coyuntura siendo posible ajustar conforme las fluctuaciones del mercado (p. 94).

Esta dinámica empresarial de colocación e intermediación de fuerza de trabajo no se puede tener como si esencialmente cumpliesen una función social, al poder entregar estadística de desempleo y de poder brindar a las empresas contratantes un perfil del trabajador como lo afirma Mazza (2003), aceptar esta tesis en absoluto sería dar razón a que el mercado de trabajo en si opera en su propia lógica y sin lugar a discusión efectivamente se comercializa la fuerza de trabajo.

Por el contrario, estas empresas son el reflejo de una organización eficiente del mercado de trabajo que ha precarizado las condiciones de los trabajadores al establecer formas atípicas contractuales de vinculación laboral, que puede ir más allá de la posibilidad de encontrar un empleo, en tanto que posterga la movilidad social del trabajador mismo y de su núcleo familiar.

Las formas contractuales que se utilizan para establecer los vínculos laborales, no dan prioridad a la garantía de los derechos que las disposiciones legales consagran, subsumiendo a un segundo plano tales prerrogativas, utilizando formas inusuales contractuales que terminan en fenómenos entre los que se encuentra la denominada tercerización laboral.

La tercerización laboral como fenómeno es el fruto de las tendencias económicas, ajustadas a formas efectivas de la organización de la producción que involucra la fuerza de trabajo, y lo vuelve uno de sus elementos para efectivizar el rendimiento de los beneficios económicos que favorece a la clase empresarial y que va en detrimento de los derechos de los trabajadores.

Tal fenómeno ha sido objeto de análisis en la medida que es parte integral de la flexibilización laboral, mediante el cual una actividad laboral determinada puede ser desarrollada por los trabajadores de una empresa y se transfiere a otra empresa contratista que interviene en la producción o en la prestación de un servicio (Ermida \& Colotusso, 2009).

Sin embargo, la tercerización encierra en sí misma un primer vínculo que se da a través de la relación de trabajo, figura jurídica que puede estar sujeta a la facultad del empleador de establecer las condiciones contractuales a las que se sujeta la relación de trabajo, de modo que permite establecer figuras contractuales atípicas y el surgimiento de formas asociativas como condicionamiento para la vinculación efectiva de los trabajadores.

Este es uno de los métodos más efectivos que las empresas implementan y que degrada los derechos de los trabajadores, eliminando del medio laboral la estabilidad como principio, y se convierte en un obstáculo para la realización de 
derechos fundamentales como el de asociación sindical, no obstante, las formas asociativas cooperativistas $u$ otras civiles son de aceptación en el medio empresarial por cuanto permiten establecer relaciones de trabajo encubiertas, o simplemente se evita establecer un vínculo contractual directo, aparejando como resultado la intermediación.

La tercerización tiene como efecto dejar al trabajador frente al empleador, para establecer una relación de trabajo sujeta a la individualidad, haciéndolo vulnerable al despido y la inestabilidad, por cuanto el contrato individual de trabajo no se discute en ninguna condición, así como el que se determine unilateralmente su término, sin dar lugar a discusión.

Este es tal vez el efecto de las economías de mercado y dentro de las cuales las reglas no se traducen en gran medida en beneficios sociales de la clase trabajadora, por el contrario es la razón por la que el sistema económico tiene irresistibles efectos sobre la organización de la sociedad, en tanto que la sociedad es gestionada y auxiliar del mercado (Polanyi, 2007).

\section{MERCADO DE TRABAJO, GLOBALIZACIÓN Y NEOLIBERALISMO}

La globalización es un proceso de integración económica y comercial en el mundo, cuyas políticas dentro de un marco económico han tenido avances positivos por ser este su principal objetivo, sin embargo, ha tenido un efecto negativo que impacta los mercados de trabajo.

La globalización como la concibe Beck (1998) permitió reconquistar y negociar política y al capitalismo organizado democráticamente, posibilitando que los empresarios desempeñaran un papel clave, no solo en la economía, sino también de la sociedad, privándola de los bienes materiales, entre estos, los puestos de trabajo, los que se pueden reducir o rarificarse para incrementar los beneficios, donde el fomento del crecimiento económico acaba generando desempleo, y así mismo, la reducción drástica de impuestos para el aumento de probables beneficios termina posiblemente generando desempleo.

Así entonces, la economía no es marcada por las relaciones sociales, por el contrario, son las relaciones sociales las que se ven encasilladas dentro del sistema económico, cuya existencia excluye cualquier otro tipo de relación, y al estar organizado sobre sus estatutos, obliga a la sociedad a adoptar la forma que permite al sistema seguir sus propias leyes (Polanyi, 2007).

Por otro lado, los adelantos tecnológicos se dieron de alguna forma tardíos o lentos en un lapso hasta de siglos en determinados momentos de la historia, al contrario de lo que hoy sucede en todos los ámbitos, dado a que se experimentan cambios sustanciales y vertiginosos en la tecnología, de alguna forma afecta a los trabajadores y al tipo de relaciones de trabajo que se establecen con las empresas organizadas según las reglas del mercado. 
El reemplazo de trabajadores por máquinas como lo señala Gorz (1991) segmenta y desintegra la clase obrera, formando una elite reducida que colabora al capital, condenando a la precariedad y marginando una mayoría, como una reserva industrial que cree poder ajustar a las variaciones de la demanda (p. 94).

Así sincrónicamente la organización del trabajo cambió con el sistema de mercado acompañado de la organización social (Polanyi, 2007) que basó en el derecho del trabajo la estructura de un cuerpo normativo para dar una solución justa a una cuestión social, asegurando un mínimo de derechos y garantías en la prestación del trabajo, compatible con la dignidad de la persona humana, particularmente en las relaciones de dependencia frente a su empleador (Oficina Internacional del Trabajo, 2005).

Pero en la medida en que el empresario o empleador encuentra en los mecanismos jurídicos los vacíos suficientes, instrumenta e implementa métodos de la organización productiva eficaces, en tanto que la permisividad del mismo marco laboral laxo y obsoleto, apareja un sistema de administración de justicia paquidérmica, que no los hace efectivos o es tortuosa la realización de la justicia laboral, repercute socialmente tanto en las condiciones laborales como por fuera de estas, que se traduce en el retraso de la movilidad social.

Las consecuencias sociales, la transición a la nueva economía, las revoluciones sociales son el resultado de esos cambios (Hobsbawm, 2007), que no solo involucra a simples trabajadores con salarios de subsistencia sino que también involucra a pequeños comerciantes al punto de la marginación y del ejercicio económico.

Por lo tanto, el trabajo, como lo señala Polanyi (2007) es uno de los componentes esenciales de la industria, el cual debe estar también organizado en el mercado, formando en realidad una parte fundamental del sistema económico (p. 127).

En este mismo sentido, el mercado de trabajo para Korinfeld \& Neffa (2006) es el resultado de la relación social estructurada por instituciones que regulan las relaciones entre empleadores y buscadores de empleo, y que finalmente solo se involucran las dos partes: empleador y trabajador, al establecer la relación de trabajo (p. 14).

Tales apreciaciones pueden observarse, además, teniendo en cuenta el que la finalidad misma puede tener la bilateralidad del contrato de trabajo, no es en esencia consensuado, toda vez que el contrato de trabajo, su forma, el período de duración y la retribución, entre otros, son aspectos que no se someten al consenso de las partes, y menos que la autoridad incida en la actuación.

Los mercados de trabajo como lo afirma Polanyi (2007) sin que haya lugar a un atisbo de duda, son esenciales para la economía de mercado, cuyo propio proceso de producción se soporta sobre el pilar de la compra y venta donde no hay cabida para otro modo en las sociedades comerciales.

Pero este no es el único efecto, el salario en el mercado de trabajo actúa como un instrumento de ajuste entre la oferta y la demanda, cuyo nivel salarial pagado 
por las empresas es el fin de una transacción comercial fijado dentro de la base que ha determinado el mercado (Korinfeld \& Neffa, 2006).

Ahora, desde la perspectiva empresarial neoliberal son válidos estos mecanismos que procuran la mejora de la competitividad, y estos pueden comprender el contratar con empresas especializadas que no implica necesariamente procesos productivos, sino que también comprende el objetivo de reducción de costos del personal, tanto cualificado como semicualificado, lo que finalmente refleja un indicador favorable de competitividad para la empresa.

Visto de este modo, las relaciones de trabajo se soportan en vínculos contractuales con empresas que se dedican a la oferta de fuerza de trabajo, lo que en últimas se traduce en objeto de comercialización, definida inicialmente en una relación contractual entre agencia de empleo, empresa de servicio temporal u otra forma de intermediación, con la empresa usuaria de esos servicios, subyaciendo finalmente sobre esta forma contractual comercial las relaciones de trabajo, efecto triangular que va en detrimento de los derechos de los trabajadores colocados o temporalizados, por cuanto el objeto inicialmente no es brindar garantías a sus trabajadores al estar por encima el interés comercial entre contratante y contratista, cuyo efecto precariza las condiciones laborales y sociales de la clase trabajadora.

La lógica neoliberal sustrae en términos de intervención y reducción al Estado, en la medida que distorsiona los propósitos elementales de los contenidos axiológicos de las disposiciones superiores internas, subyaciendo un marco regulador permisivo que da al empresario la ventaja de la producción más rentable, que no es más ventajosa para los usuarios, cuya resultante global obedece a los límites que impone la iniciativa capitalista (Gorz, 1976, p. 151).

Finalmente, formas de trabajo y relaciones de trabajo, en una $\mathrm{u}$ otra época no tuvieron esencialmente un objeto diferente que tener una fuerza de trabajo a disposición para la obtención del beneficio comercial como fin principal. Así mismo, el efecto dentro de la organización económica y productiva, de la que no es ajena la fuerza de trabajo, se organiza de forma eficiente, tanto para dar solución a la demanda como de la forma efectiva de establecer esas relaciones laborales, atendiendo a las fluctuaciones del mercado, además de estar sujetas a un marco regulador permisivo y un deficiente control de las autoridades, que termina degradando las condiciones de la clase trabajadora expuesta a la regencia de los fenómenos de la globalización y del neoliberalismo.

En este orden de ideas, es preponderante en un sistema neoliberal y su lógica, considerar prioritarias las actividades rentables, así mismo el descuidar las actividades cuyo producto o resultado no se midan con el criterio de la rentabilidad y el rendimiento (Gorz, 1976, p. 151).

Por lo tanto, los mercados de trabajo comprenden una de las aristas que se desprende de las necesidades del mundo globalizado mercantilmente, y el cual, en la reformulación neoliberal este juega un papel determinante al ser una justificación 
para la organización del trabajo que solo impulsa los intereses del mercado, que involucra la fuerza de trabajo, no desde una óptica social, pero sí comercial.

En las relaciones de trabajo si bien se dista de lo que en uno u otro régimen antiguo se institucionalizó, pese a los avances jurídicos, los hombres que hoy gozan de libertades en cuanto les permite ser dueño de su voluntad, pero como tal, desposeídos de todo bien, dejan de serlo, frente a la necesidad.

\section{CONCLUSIONES}

Dentro de los diferentes sistemas de producción adecuados en cada momento de la historia a los intereses comerciales, con estos ha surgido siempre la imperiosa necesidad de disposición de una fuerza de trabajo que se amolde o sujete a la fluctuación misma de la exigencia de uno u otro modelo de mercado, que permita una efectiva disposición de la misma, apacible y dócil, manejable y atomizada, que no tenga sentido de lucha colectiva y que acepte las condiciones que oferta el mercado sin iniciativa de resistencia a dichos condicionamientos.

Las tendencias de mercado deben de involucrar modelos economicistas para el comercio, sin que permee los objetivos estatales sociales, que se pueden ver menguados cuando el ejercicio libre del comercio no tiene un control efectivo por la convergencia de los dos propósitos, comercial y social, y que de manera indiscutible en ambos casos, están implicadas las personas como actores, con intereses que divergen para unos y otros, pero que en el elemental propósito de los fines, siempre se encontraran formando relaciones dentro de un marco jurídico del que se predica protector, pero que en la práctica se puede convertir este en el punto de partida para evadir tales propósitos institucionales, que justifique la prioridad de los propósitos económicos dentro de un ámbito de flexibilidad para el mercado, arrastre consigo la pauperización de una clase trabajadora sin alternativas, que les permita avanzar hacia el reconocimiento pleno de sus derechos.

\section{REFERENCIAS}

Baylos, A. (1998) Globalización y derecho del trabajo, Realidad y Proyecto. Universidad de Castilla. La Mancha. Cuadernos de Relaciones Laborales, $N^{\circ}$ 15, Serv. Publ. UCM, Madrid 1999. Recuperado 01/07 2015https://revistas.ucm. es/index.php/CRLA/article/download/CRLA9999220019A/32488

Beck, U. (1998). ¿Qué es la globalización? Falacias del globalismo, repuestas a la globalización. Barcelona: Ed. Paidós Ibérica.

Conferencia Internacional del Trabajo, 95a reunión. (2006). La relación de trabajo. Oficina Internacional del Trabajo. Recuperado de http://www.ilo.org/public/ spanish/standards/relm/ilc/ilc95/pdf/rep-v-1.pdf 
Confederación Sindical de Trabajadores y Trabajadoras de las Américas CSA \& Confederación Sindical Internacional - CSI. (2013). Tercerización Mediante Agencias de Trabajo Temporal en América Latina. Campaña Libertad Sindical, Negociación Colectiva y Autorreforma Sindical. Recuperado de www.csa-csi.org

Domínguez, D.J. (2008). Los poderes feudales. Las maneras de la extracción del excedente en la economía medieval. Nómadas, Revista Crítica de Ciencias Sociales y Jurídicas, 17. Universidad Autónoma de Madrid.

Escobar, A. (2014, julio-diciembre). Instituciones y trabajo indígena en la América española. Revista Mundos de Trabajo, 6(12), 27-53. Recuperado de https://periodicos.ufsc.br/index.php/mundosdotrabalho/article/viewFile/19849222.2014v6n12p27/29730

Ermida, O., \& Colotuzzo, N. (2009). Descentralización, tercerización, subcontratación. Lima: Oficina Internacional del Trabajo.

Finley, M. I. (1982). Esclavitud antigua e ideología moderna. Barcelona: Ed. Crítica.

Gómez, Á., \& Casal, I. (1996, enero-abril). La regulación del trabajo en Roma y la moderna Legislación Española. Revista de Derecho Privado, 19(7). México. Recuperado el 20/03/2016 http://www.juridicas.unam.mx/publica/librev/rev/ revdpriv/cont/19/dtr/dtr3.pdf

Gorz, A. (1976). Estrategia obrera y neocapitalismo. México: Biblioteca Virtual Omegalfa, Editorial Era S.A.

Gorz, A. (1991). Metamorfosis del trabajo. Búsqueda del sentido. Crítica de la razón económica. Madrid: Editorial Sistema.

Hobsbawm, E. (2007). La era de la revolución. Grupo Editorial Planeta. Buenos Aires.

Jaramillo, I.D. (2010, julio-diciembre). Presente y futuro del trabajo: Breve historia jurídica del trabajo en Colombia. Opinión Jurídica, 18(9), 57-74. ISSN 16922530. Medellín, Colombia.

Korinfeld, S., \& Neffa, J.C. (2006). Los intermediarios del mercado de trabajo. Buenos Aires: Clacso. Recuperado el 02/08/2015 de http://bibliotecavirtual. clacso.org.ar/Argentina/ceil-piette/20121211052845/doc41.pdf

Marx, K. (1984). El Capital. Libro Primero. Madrid: Siglo XXI.

Marx, K. (1999). Formaciones económicas precapitalistas. Madrid: Siglo XXI.

Mazza, J. (2003, agosto). Servicios de intermediación laboral: enseñanzas para América Latina y el Caribe. Revista de la CEPAL, 80, 166-183.

Oficina Internacional del Trabajo. (2005). La reforma laboral en América Latina: 15 años después. M. L. Vega Ruiz (ed.). Organización Internacional del Trabajo. Lima. Recuperado de http://www.oit.org/wcmsp5/groups/public/---americas/--ro-lima/---ilo-buenos_aires/documents/publication/wcms_bai_pub_2.pdf

Organización de las Naciones Unidas para la Educación, la Ciencia y la Cultura. (1997). La ruta del esclavo. Recuperado de http://unesdoc.unesco.org/ images/0011/001144/114427So.pdf 
Ostau de la Font, Francisco R. (2006) El discurso paternalista en la formación de la norma laboral. Universidad Externado. Bogotá. Colombia.

Polanyi, K. (2007). La gran transformación. Critica del liberalismo económico. Madrid: Quipu Editorial. Recuperado www.quipueditorial.com.ar

Rodríguez, O.M. (2014). El intermediario y el derecho del trabajo mexicano. Universidad Autónoma de México, Instituto de Investigaciones Jurídicas. Recuperado de http://biblio.juridicas.unam.mx/libros/libros.htm?l=3809

Valencia, A. (1987). Encomiendas y estancias en el Valle del Cauca, siglo XIX. En Historia y Espacio. Revista de Estudios Regionales, 11-12, 25-26. Cali. Universidad del Valle.

Zingarelli, A.P. (2004). La esclavitud en el Egipto del imperio. Colección de Estudios de Egiptología. Ed. ASADE. ISBN 84-933485-2-X. Recuperado de www.egiptologos.com 